\title{
Culture in L2/Ln Sign Language Pedagogy
}

\author{
M. Diane Clark ${ }^{1}$, Chong Min Lee ${ }^{2}$ \\ ${ }^{1}$ Lamar University, Beaumont, TX, USA \\ ${ }^{2}$ Metro School for the Deaf, St. Paul, MN, USA \\ Email: ${ }^{\star D i a n e . c l a r k @ l a m a r . e d u ~}$
}

How to cite this paper: Clark, M. D., \& Lee, C. M. (2018). Culture in L2/Ln Sign Language Pedagogy. Creative Education, 9, 1897-1909.

https://doi.org/10.4236/ce.2018.913139

Received: September 20, 2018

Accepted: October 15, 2018

Published: October 18, 2018

Copyright $\odot 2018$ by authors and Scientific Research Publishing Inc. This work is licensed under the Creative Commons Attribution International License (CC BY 4.0).

http://creativecommons.org/licenses/by/4.0/

(c) (i) Open Access

\begin{abstract}
There are diverse reasons for learning a sign language, including taking courses for personal use versus taking courses for formal academic credit. Those learning a sign language for personal reasons include people who interact with deaf people; they may have a deaf child or work in a deaf-hearing environment. These personal users require different curriculums and frequently have different goals in terms of their final levels of proficiency. Learning a sign language as a foreign, or world, language tends to follow the long-established standards for any foreign language learner. For sign languages, multiple projects are ongoing to create more effective curriculums to achieve the "5Cs" listed within the US accrediting standards and the "Can Dos" in the European standards. There is the need for additional research in sign language curriculum development as well as pedagogy for the most effective transmission of sign language skills and their associated cultural components. Future efforts to develop curriculum for personal users as well as those in formal academic settings will provide highly skilled sign language instructors as well as interpreters.
\end{abstract}

\section{Keywords}

Sign Language, Environment, Curriculums, Culture

\section{Introduction}

What is the impact of culture as we engage with learning a new language, especially if that language is a sign language? Here are some of our own personal experiences in this journey of becoming a bimodal bilingual language user. First let us define bimodal bilinguals; sign language receives visual inputs and uses manual outputs while spoken language receives aural inputs and uses oral outputs. Therefore, two different sensory systems are involved as we function as bilingual language users. This modality difference can also be seen in the cultural aspects 
of our experiences.

As a hearing, European American woman, my experience with learning a sign language began when I was a Ph.D. student and began a research agenda focusing on information processing in deaf individuals. After completing my dissertation, I got a post doc position at Gallaudet where they PAID me to learn American Sign Language (ASL). Many of my instructors were native signers and the program included many Deaf cultural experiences. Storytelling was an activity that helped us to understand the life experiences of growing up Deaf in a hearing family. These stories helped us to begin our cultural journey into a visual world. Teaching improved my fluency as the students were generous in sharing their sign language and Deaf cultural knowledge with me.

As a Deaf Korean woman, who grew up in a hearing world, I thought learning another language was something I was unable to enjoy until I learned Korean Sign Language (KSL). I was surprised at my motivation. I remember I enrolled in a KSL class once. The teacher taught us sign vocabulary only by topics such as family, foods, weather, and education but we never discussed Deaf culture in class. I was not motivated to learn KSL, so I dropped the class. Instead, I decided to attend Deaf community events to acquire KSL more naturally.

My ASL learning also happened this way in the U.S. when studying for my $\mathrm{Ph} . \mathrm{D}$. Through interacting with other Deaf and hearing signers in natural settings, I was able to immerse myself in American Deaf culture and pick up new signs quickly, I also observed different cultural behaviors-different from my original hearing cultural traditions. These learning experiences enabled me to understand practically how language is intricately related to culture. In addition, from my own experience teaching ASL for many years, I find that hearing students tend to have a greater motivation for language learning when Deaf culture is embedded within the course content.

Our own personal experiences convinced us that language is embedded within culture and that learning the grammar without understanding the surrounding culture of those who use a language will not permit one to become a fluent user of that language. Our personal experiences emphasized the relationship between language, identity, and culture. Now we turn to a review of the literature related to language and culture.

\section{Literature Review}

In the 1970s, the fields of sociolinguistics and psycholinguistics emerged, changing how we perceived language with the work of Roger Brown, Ursula Bellugi, Joshua Fishman, Eve Clark, Michael Halliday, and Del Hymes, among others. Rather than focusing on only the grammar of a language, the functional notional or communication-based model emerged where the study of language is embedded within social situations (Paige, Jorstad, Siaya, Klein, \& Colby, 2000). Now, culture and language are seen as integrated where language is both the shaper and the expression of culture (Paige et al., 2000). These changes 
impacted how language was taught and led to discussion of how language and culture are interrelated.

Brooks's (1968) classification of culture was used to identify a foundation for the list of topics that should be taught in the language classrooms. He identified five meanings of culture: biological growth, personal refinement, literature and the fine arts, patterns for living, as well as the sum total of a way of life. Of the five components, Brooke's suggested that the fourth meaning of culture (i.e., patterns for living) would be useful for language learning at least in beginner-level language courses. The integration of these various definitions of cultures, develops both an external context, or the meanings that culture attaches to various social and linguistic events, as well as an internal context that individuals bring with them to these social encounters (Byram \& Feng, 2004).

When we integrate language and culture, we are preparing students to be cultural learners (Paige et al., 2000). Therefore, the language learner has first to understand their own culture, leading to a discovery of the relationship between language and culture, and finally to an understanding of how to compare cultures. This cross-cultural comparison allows the language learner to understand varying epistemologies (Jurasek, 1995). Therefore, language is larger than the words on the page, it includes the cultural context that created the words.

Byram, Gribkova, and Starkey (2002) see social relationships as the basis for being an effective intercultural mediator. If one is able to respect how culture influences social interactions, one is able to demonstrate the linguistic competence needed to demonstrate intercultural competence. Here it is not necessary to be as fluent as a native speaker; rather the successful culturally competent speaker can interpret and relate to varying social identifies.

Given these views of culture and language, there are varying reasons for an individual to become an L2 learner. In regards to sign language, it may be a child whose family decided to use spoken language and later finds that their child was not successful and is now moving to using sign language as their primary language. This late switch in language creates two different groups of learners, the child themselves as well as their family. Others may need to learn a sign language to interact with deaf individuals at work; they may work in vocational rehabilitation, early intervention, as a teacher, or at a bilingual university like Gallaudet or the National Technical Institute for the Deaf. Here we are using the term "personal use" to refer to these individuals. For the child, their learning frequently is through immersion where they are moved to a school environment that is bilingual. For these children's parents, they frequently take sign language classes through churches and local deaf agencies. Typically, those who need sign language for work related activities also take less formal instruction that is ungraded. In contrast to this group, is the group either in $\mathrm{K}-12$ or postsecondary institutions who are taking sign language courses for credit. There are some important differences between these groups in terms of curriculum and which cultural values are emphasized. Below we present these ideas. 


\section{L2 Acquisition of a Sign Language Related to Personal Use}

Many countries are developing projects for families to help them learn sign language to be able to communicate with their deaf children. Typically, a Department of Education works with organizations that support deaf children and their families. In the UK, the Department of Education created the I-Sign project which is delivered by a consortium of deaf organizations (http://www.i-sign.org.uk)/. This project has developed a Family Sign Language curriculum to meet the needs of these families, rather than traditional British Sign Language (BSL) courses which are targeted to adult audiences. The curriculum teaches families tips on how to engage with their deaf child as well as how to tell stories. One interesting link at ndcs.org.uk is Make Christmas deaf friendly that provides information about how to involve the deaf child in Christmas activities with suggestions about background noise, lighting, and conversation at dinner. The I-Sign project's goal is to provide free beginning classes as well as funding for more advanced classes if the family desires.

A joint project in the Netherlands and Canada also has created a sign language curriculum for parents (http://www.signimpact.nl/ or

https://Carleton.ca/slals/people/snoddon-kristin/). This project worked on infusing best practice solutions based on research into earlier informal teaching. These researchers based their seven modules on the Common European Framework of Reference for Languages (CEFR) standards of A1 to B2, which are beginning or breakthrough levels, through waystage to threshold. Here, parents are encouraged to choose their own learning goals, which match the needs of their families. In addition to these modules, Snodden (2014) focused on story book reading in Canada using an ethnographic perspective. The two families in her study wanted to learn vocabulary but tended to continue to read the stories word for word. Both of these projects, highlight the need for communication that can be at the basic user level, rather than at a highly proficient level to meet the needs of young deaf children and families.

Australia has a similar program for families to learn Auslan, established by Deaf Children Australia (deafchildrenaustralia.org.au). Here the goals are to remove barriers so that children develop linguistic and social competencies that are age appropriate. A family sign class is offered to support the learning of Auslan for the whole family. During these sessions, supervised recreation is provided to the children for part of the class to develop peer networks. The group also teaches families how to advocate for the needs of their deaf children. There is no information about how Deaf culture is introduced into the program but it can be assumed that the introduction of deaf children to each other and potentially other deaf adults will lead to learning Deaf culture.

These examples are not the only ones that have been developed, but information on these types of curriculum tend to be more applied and not research based. Information is shared locally to aid in the development of deaf children and those who interact with deaf people. Therefore, it is difficult to find detailed 
information. Next, we turn to L2 acquisition for academic credit.

\section{L2 Acquisition in Formal Settings}

Sign languages are currently offered in universities around the world, in the UK, New Zealand, Italy, Germany, and Finland to name a few. More than 210 universities and colleges teach ASL in the US, where ASL is the third most popular modern language. In the past 15 years, as this change has spread from one college to the next, the demand for ASL teachers in both K-12 settings and university has risen faster than programs can graduate students. This demand has aided the Deaf community as Deaf culture classes are embedded within these programs.

Given this dual focus on intercultural competence while using a language, Byram and Feng (2004) suggest that teaching students how to become an amateur ethnographer is beneficial. This methodology encourages a critical perspective of both one's native language and one's L2. Hymes (1974) as cited in Byram \& Feng (2004) focused on the understanding of context within the field of cultural studies. He believed that there are eight factors that are essential within the context of intercultural communication, which he summarized as SPEAKING. These factors include Setting, Participants, End (the goal of the utterance), Act sequence (the form and content of a statement), Key (non-verbal components), Instrumentalities (choice of channel), Norms (for interactions and their interpretation), and Genre. Embedded within Hymes' SPEAKING is the comprehension that it is not only the grammar and vocabulary that allows one to be a competent communicator in an L2, but that a culture's history, the situation, and one's position within society all are vital to effective communication. Therefore, instructors need to help learners explore cultural contexts and be sensitive to clues about "unwritten" or implied cultural norms. Byram and Feng (2004) believe that learning how to conduct ethnographic interviews leads to real and active participation within the culture of the L2. The end result of learning this ethnographic method is that students develop, not only linguistic competence but intellectual growth. Here it becomes clear that student motivation (see also Byram \& Feng, 2004) and integrating culture into the language classroom lead to the most effective outcomes for L2 learners. Next, we look at the research about culture and language regarding sign language instruction.

There is little research about how Deaf culture should be integrated into the formal teaching of sign languages. One early paper by Smith (1988) explain how her team decided to write the Vista American Sign Language Series. Signing Naturally (Smith, Lentz, \& Mikos, 1988). She noted that "very little attention had been given to cross-cultural interactions" (p. 172) in the early teaching of ASL at Vista College. They wanted a text that provided a natural context for sign language learning and "concluded that the 'functional-notional' approach" (p. 174) by Finocchiaro (1983; as cited in Smith, 1988) would be best. They wanted to create cultural awareness and to accomplish this goal they collected natural 
language samples to better understand the interaction between language and culture. These samples included groups of all Deaf people as well as between mixed groups of Deaf and hearing people. At the time sign language teachers were not trained in the teaching of sign as a foreign language; therefore, Smith and her team wanted a curriculum that permitted hearing students to learn how to communicate with Deaf people in the most likely natural situations that they would experience.

Quinto-Pozos (2011) provides an interesting review of teaching ASL to hearing adult students. He noted that we have not investigated the effectiveness of the pedagogical strategies that have become common in teaching sign as an L2. Quinto-Pozos suggests that most strategies for sign language teaching are based on both the linguistic and cultural beliefs of the instructors. These instructors are both Deaf and hearing. Hearing instructors can be those who learned ASL early and are more native like in their linguistic knowledge or hearing instructors who learned the language later. This wide variation in instructors will alter the pedagogical strategies used in the classroom, making it vital that we investigate their efficacy for L2 learning.

Quintos-Pozos (2011) notes that because Deaf individuals have been a linguistic and cultural minority, which has historically been oppressed, this issue must be addressed within the sign language L2 classroom. Given this history, the decision to permit spoken language in the classroom to teach a visual/manual language is strongly connected to this oppression and how Deaf people value visual language. Naturally if the instructor is Deaf, more traditionally cultural strategies are used to overcome communication barriers; such as written literature, pictures, gestures, or role plays to aid in getting the information across through the visual channel and help the hearing L2 learner rely less on their auditory channel. Many people believe that "only Deaf and hard of hearing candidates are appropriate candidates for ASL instructor positions" (p. 145). Therefore, the hearing status of the sign language L L2 teacher comes into play when teaching culture to the beginning sign language learner.

Regardless of one's beliefs about whether or not the sign language instructor should be Deaf or not, currently most courses include Deaf culture as part of the curriculum. This infusion of Deaf culture allows the inclusion of how to break away from the traditional sequential grammatical structure of spoken languages. It becomes an effective bridge to using space in a parallel way with a visual spatial grammar. This pedagogy was not that used in the 1970s, when teaching sign language focused mostly on learning vocabulary rather than "the complex grammar of a visual-spatial grammar" (Peterson, 2009; as cited in Quinto-Pozos, 2011: p. 143). This lack of instruction on the grammar of sign frequently was confusing for hearing L2 learners, as they simply used sign vocabulary in spoken language grammatical structures. Therefore, when teaching any sign language, the inclusion of Deaf culture is vital to the effective learning of a visual manual language. 
Professional organizations, referred to as Special Interests Groups or SPAs, oversee curriculum and insure that there are standards that are taught in postsecondary teacher training programs, which help in more effective teaching. The SPA for teaching foreign languages in the US is the Phillips \& Abbott (2011) who developed standards that are often referred to as the "5Cs". They include the five goals of Communication, Cultures, Connections, Comparisons, and Communities. Here the focus is on the inter-relationships between language and culture to understand how one's own language and culture compares and contrasts to the language and culture under study. Then American Sign Language Teachers Association (ASLTA) adopted these standards to create more effective curriculums and policies related to the teaching of ASL, again following the “5Cs".

In Europe, CEFR approached the issue from a competency-based perspective and includes six reference levels for speaking, reading, listening, and writing skills. These levels are A1-Breakthrough, A2-Waystage, B1-Threshold, B2-Vantage, C1-Effective Operational Proficiency, and C2-Mastery. Here A levels are basic users, B levels are independent users, and C levels are proficient users. These CEFR levels map linguistic materials with the competencies needed to the task needed in the domain of use (Using the CEFR: Principles of Good Practice; cambridgenglish.org).

These professional organizations work to provide guidance for establishing policy, creating curriculums, and developing assessments. For example, CEFR has principles for teaching and learning as well as for assessment. ASLTA is currently providing certification for those that teach ASL at all levels, not only the postsecondary level. ASLTA is working with state departments of education to integrate their own certifications into a national level of certification. These professional organizations are important in helping to integrate new theory and policy into language learning classrooms.

Formal postsecondary curriculums have been developed for some sign languages while others have yet to approach the teaching of sign language from a standards-based curriculum. Finally, other countries are just now developing sign language instruction at the postsecondary level (i.e., Saudi Arabia). Below we discuss some of these developments and briefly point to others.

UCLAN in the U.K., created a project to develop a BSL curriculum to be used in higher education (bslqed.com), ultimately labeled BSL: Quality Embedding of the Discipline or BSL: QED. Prior to this time there were no benchmarks for BSL at the postsecondary level and the available resources were extremely limited. The project used the CEFR framework and their materials are available on the web. Funding was obtained from the British government with a goal to create a BSL-website called Sign-Online. This project was a collaboration of UCLAN and UCL as well as DCAL. The overarching goal is to increase the numbers of BSL teacher and interpreters with well-designed benchmarks that can use the types of assessments developed by the CEFR. Curriculums from 
across the globe were collected for review, including VISTA from the US as well as those used in Finland, Sweden, Germany, France, Spain and Holland. This research approach identified problem areas, such as what is the best order for teaching specific topics? Another issue identified was that receptive skills were not emphasized in equal proportions to productive skills. Additionally, they focused on how to integrate Deaf culture into the curriculum including non-manual features of BSL, how deaf people identify themselves, getting attention in the deaf community, name signs, telecommunication for deaf persons, and regional variation. Research on the curriculum is ongoing with the goal of providing resources for effective postsecondary teaching of BSL.

From 2012 to 2015, Leeson, van den Bogaerde, Rathann, and Haug (2016) developed common reference level descriptors for European sign languages using the CEFR framework for sign language proficiency for professional purposes. The project was developed by the European Center for Modern Languages (ECML; ecml.at) This project is referred to as PRO-Sign and focused specifically on sign language teaching in Deaf Studies and Sign Language Interpreting programs. This project is the first to specify proficiency levels for sign languages at the postsecondary level. Using the CEFR "Can Do" philosophy of CEFR descriptions were developed for receptive language, interactions, and production of sign languages from the $\mathrm{A} 1$ to the $\mathrm{C} 2$ levels.

The move to a standards-based sign language instruction within Europe impacted other countries as well. For example, at Utrecht University of Applied Sciences initially the bachelor degree in teaching Dutch Sign Language (NGT) and interpreter training used a grammar-oriented approach to teach students sign language, but a new curriculum was developed between 2010-2014 to align it to the CEFR framework (van den Broek-Laven, 2014). In Germany at Hamburg University, German Sign Language (DGS) appeared first in 1981 with a degree program started in 1993. The Institute of German Sign Language (IDGS), under the leadership of Christian Rathmann, led the university in these EMCI efforts to create curriculum for the sign language interpreting program there. In Switzerland, Shores, Hohenstein, and Keller (2014) worked collaboratively to develop Swiss German Sign Language (DSGS) teaching materials again following the CEFR guidelines. PRO-Sign has been instrumental in many European countries to identify gaps and create more effective sign language curriculums.

In another part of the world, recently Australia developed a new F-10 Auslan curriculum for second language learners. The curriculum consisted of the two strands: communicating and understanding. The role of language and culture is provided in the understanding strand

(http://australiancurriculum.biz/languages/structure).

Several ASL curricula for instructors and students have been developed since ASL was offered for foreign language credit. Most college and universities in the U.S offering ASL classes adopt the Signing Naturally curriculum, which includes not only linguistic information, but also appropriate usage and rules for social 
conversations across various situations and contexts. The Signing Naturally Teacher's Curriculum, used at the university where we work, provides lesson plans, classroom activities, materials, and cultural information along with DVDs. However, the culture information of the curriculum reflects mostly surface level content about how hearing people can interact with Deaf individuals. This issue may relate to the original goal of the Vista American Sign Language Series: Signing Naturally (1988), which was to teach hearing people how to communicate with Deaf people. Moreover, these lessons are not connected with the linguistic content of each chapter. This issue was noted by Rosen (2010), who pointed out that the Deaf cultural content covered in most of the ASL curricula are independent of the linguistic topics covered in each specific unit. The one curriculum noted by Rosen as connecting the language and culture topics was the Master ASL! curriculum.

Typically, sign language courses require that students be involved in Deaf events. These events allow the student to begin to apply both their linguistic and cultural knowledge in natural contexts. As noted by Monikowski and Peterson (2013), in the past interpreters did not learn their ASL through formal coursework; rather they learned how to sign by interacting with Deaf people going about communicating in their everyday lives. These hearing and Deaf interactions could be within a family or at Deaf events, but the hearing person was fully immersed into Deaf culture. This model is no longer the most typical and Monikowski and Peterson (2013) suggest that one way to retain this type of language learning is through the introduction of service learning components into L2 coursework.

Another strategy is to hire Deaf tutors to work with students in a sign language lab, which becomes part of the structured coursework. Having Deaf employees, Deaf faculty, and Deaf students within the environmental context increases the use of sign language by students at all levels. The side benefit to this context is that these hearing students learn Deaf culture while they are improving their sign skills.

With regard to Deaf culture, norms of behavior include eye contact, rules governing social contacts, use of visual materials, touching to get attention, $\mathrm{u}$-shaped seating arrangements in home, schools, and work environments, as well as facial expressions. These linguistic and cultural behaviors should be discussed at the earliest step of language instruction. For example, eye contact is one of the most significant cultural and linguistic behaviors in sign language and Deaf culture when communicating with Deaf people. Most sign language teachers discuss and emphasize the importance of eye contact in their first class. Unlike spoken language, sign language is a visual spatial language with its own unique grammatical features, which is different from English (Quinto-Pozos, 2011). Due to differences in the modality between both languages, hearing students may find it a challenge to learn sign only through vision in signing classrooms. 
Another cultural strategy is the use of pointing. Deaf people use pointing when indicating someone in a meeting or groups or objects in specific places; this linguistic structure is called source attribution in ASL. The pointing gestures also function as personal pronouns in ASL such as "I", "You", "He/She", "They", and "It." In Deaf culture, pointing is a culturally appropriate and acceptable behavior, unlike its role in hearing culture.

Hearing people tend to find that Deaf people are too direct when their facial expressions are exaggerated. Facial expressions are used not only to express emotions, but also to convey phonological and prosodic meaning (Wilbur, 2000). Therefore, this linguistic construction must be taught to ASL L2 learners in a way that makes it more comfortable, as they comprehend its linguistic usage. Raised eyebrows and the use of PAH!, may come more naturally if they become connected to the learners own language. For example, most hearing people do raise their eyebrows when asking a question, but it is not connected to the linguistic structure of English, rather is comes through the gesture system. In a similar manner, when hearing people exclaim that they were successful, they often has many of the gestural features of PAH!. Comparing these types of expressions in the L1 may help in applying them as phonological in the L2. Therefore, it is vital that ASL L2 instructors be highly fluent in both ASL and English and find strategies to connect the two languages.

To determine best practices for teaching, one should consider the needs of the L2 learner. For those L2 learners acquiring sign language for personal use, high levels of sign proficiency tend not to be the overarching goal. Rather, it tends to be basic communication for family or work-related issues. Cultural learning is extremely important to this group of L2 learners, who need to rapidly become "smart ethnographers" and match their linguistic competencies to a Deaf cultural context, where this change occurs for deaf children who learn sign later and need to become proficient sign language users to be successful in school. Therefore, these more personal users will need to design curriculum and instructional strategies that meet their individual needs. Cultural exposure is vital to help hearing L2 learners understand basic communication strategies with deaf people. Therefore, cultural lessons on how to introduce oneself, name signs, how to get a deaf person's attention, how to design communication rules for complete access (i.e., one-person signs at a time), and even how to design home and classroom environments become important to these learners. Voice off instruction may not be as necessary for these learners, given their own level of proficiency, but voice off learning may aid in more rapid adjustment to Deaf cultural traditions.

For L2 learners in academic settings, more formal curriculums are needed. These curriculums tend to have formal assessments included within them that evaluate both expressive and receptive sign skills. Typically, here the goal of the program is a high level of proficiency as the L2 learner tends to have an overarching goal of becoming a professional within the Deaf community. Cultural immersion is extremely important for these L2 learners who need to be aware of 
Deaf culture and how to interact within the Deaf community. Voice off instruction is recommended to provide this immersion both in the classroom and outside within the Deaf community.

\section{Future Research}

Research on teaching culture in the foreign language classroom can be found in the peer-reviewed literature related to spoken languages. In contrast, limited research has been published in peer reviewed journal on effective approaches and strategies for teaching culture in the sign language classrooms. Quinto-Pozos (2011) and Rosen (2010) note important issues that need additional research. These topics include how culture and language are taught and used in sign language classrooms.

Quinto-Pozos (2011) begins the discussion of the impact of having a Deaf versus a hearing sign language instructor. Hearing instructors sometimes use both sign and spoken language in their teaching, while Deaf instructors will use pictures, gestures, or role plays to convey information when students do not understand. We have no evidence regarding the impact of this difference and future research should investigate how the instructors own cultural values impact the learning outcomes within the classroom.

Rosen (2010) notes that we need to more clearly investigate how we integrate culture norms and linguistic content in our pedagogy. Newer technologies have impacted Deaf culture in many ways and our curriculums need to reflect these changes. As noted in Holcomb (2013) Deaf culture is how Deaf people share knowledge of how to survive in a hearing world; therefore, we need to be sure that our students understand the cultural strategies share through this community.

Given the growing numbers of hearing students enrolling in formal sign language programs, we need to investigate the cultural competence of these graduates. Native signers need to be the instructional models for hearing people who are going into teaching sign language at the primary and secondary levels. We need to have more research regarding how to be sure that these hearing students are good ethnographers and fully understand how their own hearing culture is similar and different to Deaf culture.

In conclusion, sign language instruction for L2 learners has become extremely popular. Many countries have integrated sign language into their World Language departments at the postsecondary level while many primary and secondary settings are also providing sign language instruction. The current pedagogies would benefit from more research regarding best practices as well as how best to approach the integration of sign language and Deaf culture.

\section{Conflicts of Interest}

The authors declare no conflicts of interest regarding the publication of this paper. 


\section{References}

Brooks, N. (1968). Teaching Culture in the Foreign Language Classroom. Foreign Language Annals, 1, 204-217. https://doi.org/10.1111/j.1944-9720.1968.tb00135.x

Byram, M., \& Feng, A. (2004). Culture and Language Learning: Teaching, Research, and Scholarship. Language Teaching, 37, 149-168. https://doi.org/10.1017/S0261444804002289

Byram, M., Gribkova, B., \& Starkey, H. (2002). Developing the Intercultural Dimension in Language Teaching. A Practical Introduction for Teachers. Strasbourg: Council of Europe.

Holcomb, T. K. (2013). Introduction to American Deaf Culture. New York: Oxford University Press.

Jurasek, R. (1995). Using Ethnography to Bridge the Gap between Study Abroad and Theon-Campus Language and Culture Curriculum. In C. Kramsch (Ed.), Redefining the Boundaries of Language Study (pp. 221-251). Boston, MA: Heinle\&Heinle.

Leeson, L., van den Bogaerde, B., Rathmann, C., \& Haug, T. (2016). Sign Languages and the Common European Framework of Reference: Common Reference Level Descriptors.

https://www.google.com/url?sa=t\&rct=j\&q=\&esrc=s\&source=web\&cd=8\&ved=0ahUK Ewi0uv2_lcjWAhVpiFQKHRt0BuUQFghBMAc\&url=http\%3A\%2F\%2Fwww.ecml.at\% 2FPortals\%2F1\%2Fmtp4\%2Fpro-sign\%2Fdocuments\%2FCommon-Reference-Level-D escriptors-EN.pdf\&usg=AFQjCNEubw3Lagf1CB7BFK6nVmL7oEjuYw

Monikowski, C., \& Peterson, R. (2013). Service Learning in Interpreting Education: Living and Learning. In M. Marschark, R. Peterson, \& E. A. Winston (Eds.), Interpreting Education: From Research to Practice (pp. 188-207). New York: Oxford University Press.

Paige, R. M., Jorstad, H., Siaya, L., Klein, F., \& Colby, J. (2000). Culture Learning in Language Education: A Review of the Literature. http://carla.acad.umn.edu/IS-litreview/litreview.html

Phillips, J. K., \& Abbott, M. (2011). A Decade of Foreign Language Standards: Impact, Influence, and Future Directions. Report of Grant Project.

Quinto-Pozos, D. (2011). Teaching American Sign Language to hearing adult learners. AnnualReview of Applied Linguistics, 31, 137-158. https://doi.org/10.1017/S0267190511000195

Rosen, R. S. (2010). American Sign Language Curricula: A Review. Sign Language Studies, 10, 348-381. https://doi.org/10.1353/sls.0.0050

Shores, P. A., Hohenstein, C., \& Keller, J. (2014). Deaf and Non-Deaf Research Collaboration on Swiss German Sign Language (DSGS) Interpreter Training in Switzerland. Translation \& Interpreting, 6, 47-59.

Smith, C., Lentz, E. M., \& Mikos, K. (1988). Vista Signing Naturally: Level 1: Teacher Curriculum Guide and Student Videotext. San Diego, CA: Dawn Sign Press.

Smith, S. (1988). Signing Naturally: Notes on the Development of the ASL Curriculum Project at Vista College. Sign Language Studies, 1059, 171-182.

https://doi.org/10.1353/sls.1988.0001

Snodden, K. (2014). Hearing Parents as Plurilingual Learners of ASL. In D. McKee, R. S. Rosen, \& R. McKee (Eds.), Teaching and Learning Signed Languages: International Perspectives and Practices (pp. 175-196). New York: Palgrave MacMillan.

https://doi.org/10.1057/9781137312495_9 
van den Broek-Laven, A., Boers-Visker, E., \& van den Bogaerde, B. (2014). Determining Aspects of Text Difficulty for the Sign Language of the Netherlands (NGT) Functional Assessment Instrument. Papers in Language Testing and Assessment, 3, 53-75.

Wilbur, R. B. (2000). Phonological and Prosodic Layering of Nonmanuals in American Sign Language. In. K. Emmorey \& H. Lane (Eds.), The Signs of Language Revisited: An Anthology to Honor Ursula Bellugi and Edward Klima (pp. 215-244). Mahwah, NJ: Lawrence, Erlbaum. 